\title{
Assessment of debris flow magnitude in small catchments of the lombardy alps: the val gola case study
}

\author{
Daniele de Wrachien ${ }^{1}$, Stefano Mambretti ${ }^{{ }^{*}}$ \\ ${ }^{1}$ Department of Agricultural Hydraulics, State University of Milan, Milano, Italy; \\ ${ }^{2}$ DIIAR, Politecnico di Milano, Piazza Leonardo da Vinci, Milano, Italy; *Corresponding Author: stefano.mambretti@polimi.it
}

Received 12 December 2010; revised 30 December 2010; accepted 6 January 2011

\begin{abstract}
Debris flows are among the most destructive of all water-related disasters. They mainly affect mountain areas in a wide range of morphoclimatic environments. Therefore, accurate prediction of their run out distances, magnitudes and velocities plays a role of paramount importance, in order to plan and design appropriate structural and non-structural defence measures. In this context, a number of Authors have developed methods feasible to evaluate the tendency of a catchment to generate debris flow, without giving an estimation of the magnitude. Other empirical procedures are based on the analysis of historical series of debris flow, occurred in similar environments, to assess the relationship between the catchment characteristics and the maximum movable debris volumes. In this paper, and with reference to Val Gola-a small catchment in the North-East Lombardy where debris flows frequently occur-a number of methods, belonging to each of the above mentioned categories, have been briefly reviewed and applied in order to evaluate their effectiveness and consistency.
\end{abstract}

Keywords: Val Gola Catchment; Debris Flow; Magnitude Assessment; Frequency Analysis

\section{INTRODUCTION}

Sediment transport in steep, small $\left(<10 \mathrm{~km}^{2}\right)$ catchments of the Alps is often characterised by both newtonian (flood waves of clear water) and non newtonian (debris and mud flows) behaviour. The availability of long-term series of data (e.g. volumes, magnitude, velocity and frequency) is crucial in order to provide statistically significant analyses and predictions, thus making experimental measuring stations highly valuable for the scientific community as well as for the local agencies dealing with structural protection measures and land use planning.

In Italy, like the other European countries, there is a lack of such experimental data, with a few exceptions [1-3].

In this context, a number of authors developed methods feasible to evaluate the tendency of a catchment to generate debris flow, without giving an estimation of the magnitude [4,5]. Other empirical (statistical and semi-quantitative) procedures are based on the analysis of historical series of debris flow, occurred in similar environments, to assess the relationship between the catchment characteristics and the maximum movable debris volume.

In this paper, and with reference to Val Gola-a small catchment in the North-East Lombardy where debris flow frequently occur-a number of procedures, belonging to each of the above mentioned categories, have been briefly reviewed and applied in order to evaluate their effectiveness and consistency.

\section{EMPIRICAL RELATIONSHIPS}

At present, there are no rigorous methods feasible to assess the exact probability of debris flow occurrence. Semi-quantitative methods which allow to estimate the likelihood of debris flow occurrence in a particular torrent basin have been proposed by different authors [6].

As an alternative, numerical simulation models can be used to assess the flow properties and the deposition process [7].

\subsection{Debris Flow Characteristics}

From the point of view of the evaluation of a potential hazard, the volume $M$ and the peak discharge $Q_{p}$ of a debris flow represent the most important parameters. In general, a spectrum of possible debris flow volumes 
and peak discharges can be expected to occur with different probabilities.

a) Many attempts have been made to estimate a maximum debris flow volume for a given torrent catchment. These empirical equations are usually based on the most important morphometric characteristics of a catchment $[8,9]$. It was found that these equations may overestimate the actual debris flow volume by up to a factor of 100 [2]. To overcome these uncertainties, D'Agostino [10-12] introduced a Geologic Index, which takes into account the different lithologic units of the catchment. Others followed the same path [13]. On the other hand, simplest method relies on fewer parameters, as the area [14].

b) Knowledge of the peak discharge and the associated flow velocity play a role of paramount importance when evaluating the conveyance capacity of a stream channel reaches or critical cross sections, as, for example, under bridges. It has been shown that empirical relationships can be established between the peak discharge, $Q_{p}$, of a debris flow and the debris flow volume [15].

c) Other parameters like mean flow velocity, flow cross-section, travel distance and runout distance on fan play important roles in the assessment of a debris flow potential hazard [2].

Further characteristics, observed in the field, may also be used to estimate the probability of debris flow occurrence and feature the triggering, mobilisation and stopping processes $[4,5,16,17]$.

\subsection{Probabilistic Analysis of Historical Data}

Most empirical and statistical procedures for the estimation of debris flow magnitude compute "maximum" or "extreme" possible volumes. Less information is usually available about magnitude-frequency relations, which can usefully contribute to the definition of defence measures [18].

On the whole, empirical and probabilistic predictive relationships provide an approximate assessment of debris flow characteristics and their use should be restricted to the environmental context (geological, geomorphological, climatic) where they have been developed. It has been pointed out [19] that these procedures produce very different results where employed in other geographical areas, without a previous check of their applicability in a given region.

\section{THE VAL GOLA CATCHMENT}

\subsection{Geological and Geographical Framework}

The Val Gola catchment $\left(3.5 \mathrm{~km}^{2}\right)$, located in the eastern Italian Alps (Val Camonica, Lombardy Region), belongs to the Olio river basin. The catchment shows an elliptical form, with the main axes oriented in NW-SE direction (Figure 1).

Geologically, the catchment, of great importance from both economic and turistic points of view, is characterised by different lithologies, essentially represented by

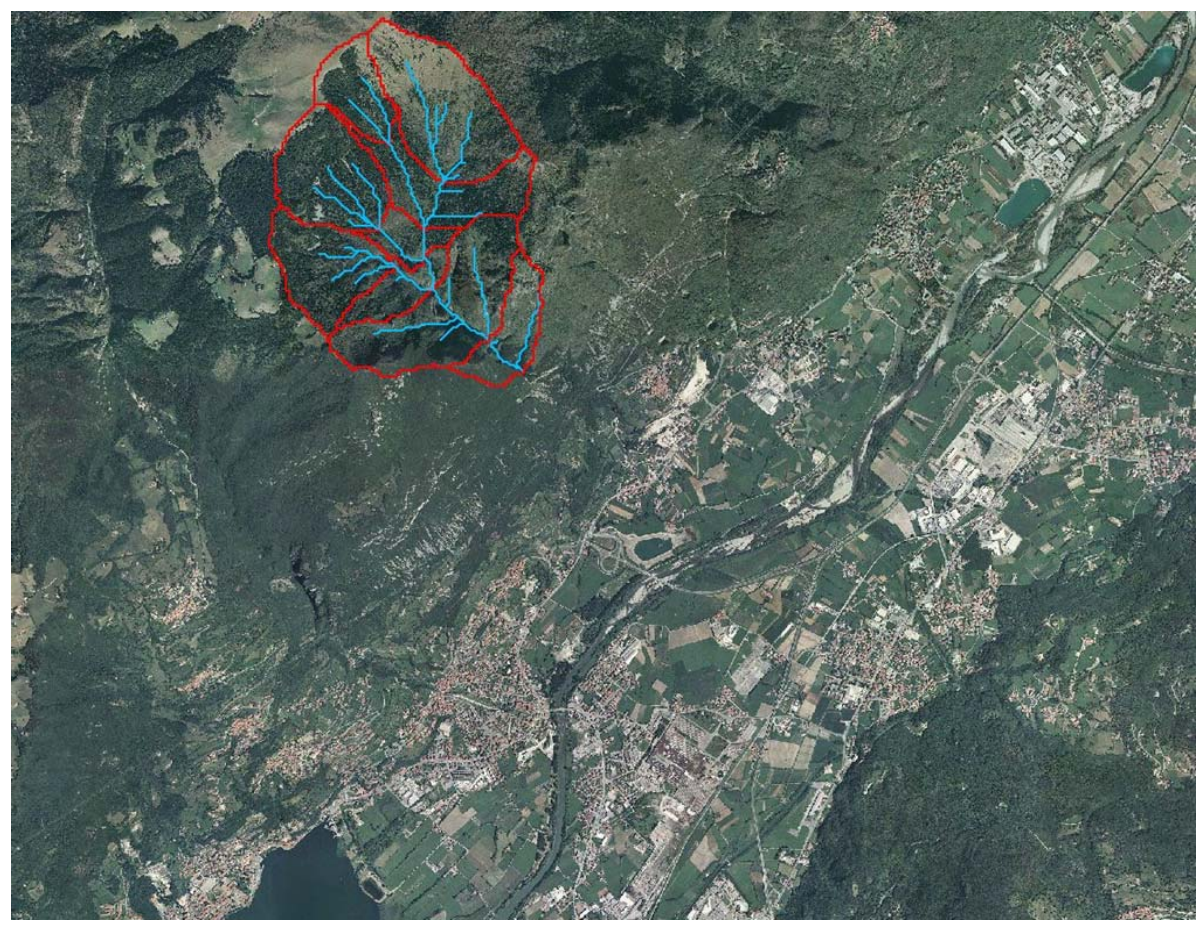

Figure 1. Location map of the study area. 
evaporite and carbonate sedimentary units (Angolo, Camorelli, and Esimo limestones) chronologically dated between low and medium Triassic. Quaternary fans are, mostly, present in the lower part of the valley. According to their genesis, these deposits can be classified as gravitative fans or screes, deposits due to the fluvial processes and glacial deposits (moraines). Upper Quaternary fans, outcropping in different areas and having different stratigraphical positions are present, mainly, in the southern part of the catchment (Fermata Castello).

\subsection{Field Surveys}

Field surveys have been carried out to directly collect data and to verify those indirectly collected by air-photo interpretation and historical sources (flood frequencies, date and magnitude of past events, damages, landsliding and areal extension of flooded areas). Based on these observations an estimation of the main debris flow characteristics (magnitude, mixture and water discharges etc.) has been carried out.

From the morphology of the fans, the knowledge of the occurred past events, the characteristics of the drainage basin and the prevalent transport mechanism associated with individual fans were determined. The main outcomes of these investigations are summarized in the following chapters.

\section{DATA ANALYSIS}

The analysis of morphometric and hydrologic parameters used to describe the catchment characteristics and behaviour was based on the most frequently adopted approaches for the assessment of the type and magnitude of dominant alluvial fan activity.

The main aims of the analysis performed in this study can be summarized as follow:

- to put in evidence any significant statistical relationship among the parameters;

- to analyse the relationships between the group of morphometric parameters and the type of activity;

- to analyse the relationships between the morphometric parameters and the feasible maximum intensity of the different events.

\subsection{Empirical Methods}

Figure 2 shows the catchment's tendency to debris flow generation according to Melton and Aulitzky's indexes, modified by Ceriani et al. [20]. The Aulitzky's index was evaluated equal to 15, featuring the bent of the basin for debris flow triggering as medium-high.

Table 1 summarizes the results of the first nine empirical relationships. It is quite evident that this formulae give only approximate estimations of the possible maximum intensity of debris flow events. Such relationships

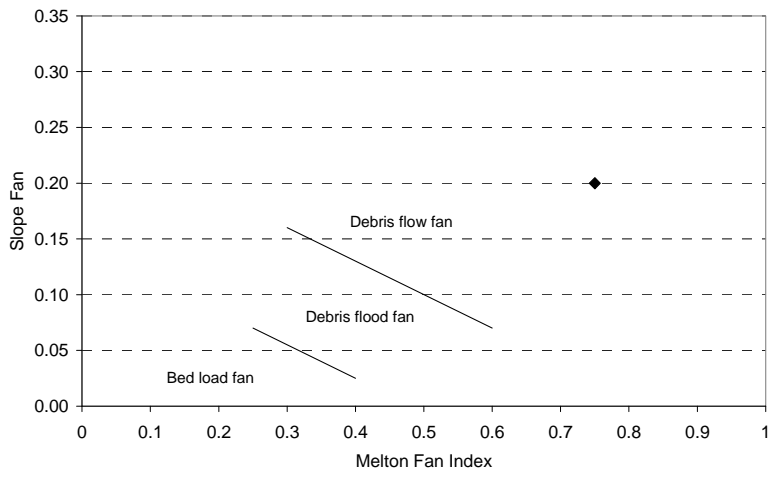

Figure 2. Catchment's tendency to the debris flow generation according to Melton index.

Table 1. Comparison of debris flow magnitude assessed by empirical relationships based on morphometric parameters

\begin{tabular}{|c|c|c|}
\hline Applied method & & Magnitude $\left[\mathrm{m}^{3}\right]$ \\
\hline Marchi and Tecca [9] & & 20440 \\
\hline Bottino, Crivellari and Mandrone [14] & & 28674 \\
\hline Rickenmann [2] & & 150000 \\
\hline Kronfellner-Kraus [16] & & 186150 \\
\hline Hampel [8] & & 296150 \\
\hline D'Agostino et al. $[10,11]$ & & $\begin{array}{l}M_{1}=51257 \\
M_{2}=58250\end{array}$ \\
\hline D'Agostino et al. [12] & & 64482 \\
\hline Bianco and Franzi [13] & & 37547 \\
\hline Tropeano and Turconi [17] & $\begin{array}{c}h=1 m \\
h=1.5 m \\
h=2 m\end{array}$ & $\begin{array}{l}42395 \\
63592 \\
84790\end{array}$ \\
\hline
\end{tabular}

can probably be improved if factors controlling sediment supply are also taken into account.

At present it appears that a geomorphologic assessment in the field of material likely to be mobilized may be the best approach to arrive at a more precise estimate of a possible debris flow volume.

It seems, therefore, necessary to test the reliability of these relationships by means of physically based methods.

Beside the above mentioned empirical formulae, the following relationship can be used, suitable to assess the rate between the debris flow $Q_{T}$ and water $Q_{W}$ discharges of the catchment [15]:

$$
\frac{Q_{T}}{Q_{0}}=\frac{c_{*}}{c_{*}-\left\{S_{b}+\left(1-S_{b}\right) \cdot c_{*}\right\} \cdot c}
$$

where $c_{*}$ is the packing concentration of the solid phase (usually equal to 0.65), $c$ is the debris flow concentration and $S_{b}$ the degree of saturation of the river bed before the debris flow passage. Assuming $S_{b}=1$ [21] the expected debris flow discharge is equal to 2-3 times the liquid discharge. The trend of the function (1) is shown in Figure 3.

The simplicity of this procedure does not prevent the assessment of the debris flow magnitude as function of 


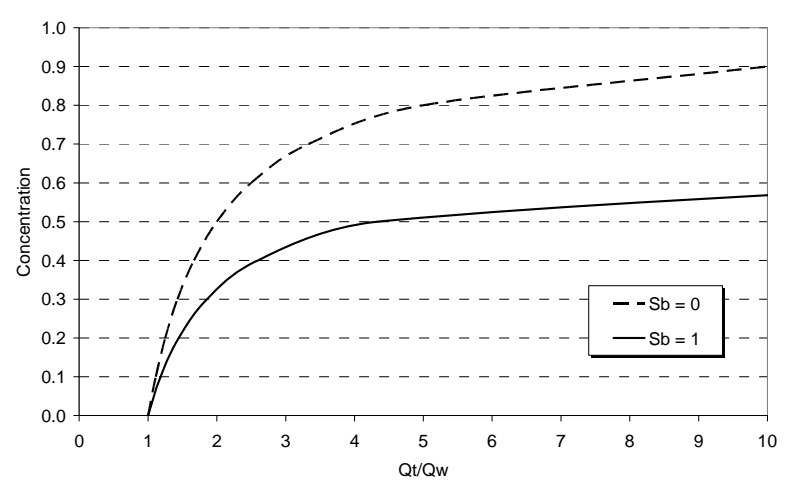

Figure 3. Ratio between the debris flow and liquid discharges Vs the debris flow concentration, with a variation of the ground saturation.

the return period, which plays a role of great importance in the design of defensive measures.

In the case of the Val Gola catchment, in order to perform these computations, the estimation of the flood wave for different return times has been carried out. To do that, starting from Depth Duration Frequency (DDF) curves of different return times, a Chicago hyetograph has been built, which is critical for any duration shorter than its base time. On the basis of these hyetographs two infiltration methods have been used: Soil Conservation Service, with $\mathrm{CN}=72$; and Horton's, considering a soil of type $C$ [22]. Depression storages have been considered equal to zero, being this assumption on the safe side, but without be exaggerated because of the very high slope of the catchment.

The rainfall/runoff relationship is of the usual convolution type, where the instantaneous unit hydrograph is the derivative of the time-area curve, normalized with respect of the total area.

The travel times have been computed considering the flow over a plane [23]:

$$
t_{c}=\frac{L^{3 / 5}}{k_{s}^{3 / 5} \cdot s^{3 / 10} \cdot i^{2 / 5}}
$$

where $L$ is the catchment length, $k_{s}$ its roughness, $s$ the slope and $i$ the rainfall intensity. The catchment roughness is a model parameter, tabled in [24], and assumed, in this work, equal to 10 .

Generally speaking, not all the discharges produce solid transport, but with the simple application of the Schoklitsch's relationship [25] it was easy to verify that, due to the very high slope, the hydrograph tails, which do not produce solid transport, are very limited.

With the described methodology, the following results have been obtained:

$$
\begin{aligned}
& \bullet T=50 \text { years, } W_{w}=75900 m^{3}, W_{t}= \\
& 150000-230000 m^{3} ; \\
& \bullet T=100 \text { years, } W_{w}=88038 m^{3}, W_{t}=
\end{aligned}
$$

$$
\begin{aligned}
& 170000-270000 \mathrm{~m}^{3} ; \\
& \cdot T=200 \text { years, } W_{w}=100807 \mathrm{~m}^{3}, W_{t}= \\
& 200000-300000 \mathrm{~m}^{3} .
\end{aligned}
$$

\subsection{Physically Based Methods}

Physically based approaches for assessing debris flow volumes are founded on the recognition of sediment sources, located along the channel network and feasible to be moved, in order to evaluate the probability of collapse. Some of these methods, known as geomorphological methods [26], assume that all eroded material reaches the alluvial fan, whereas others consider the possibility of a partial redeposition within the basin.

Generally speaking, differences in density amongst debris in source areas, flowing water-sediment mixture and debris flow deposits are usually neglected.

In this work with the term "mass of sediment" is intended a debris volume made up of a single typology of prevalent material with homogeneous dimensions and materials, which represents an approximate hypothesis.

The probability of collapse of a mass of sediment has been assessed on the basis of the typology of the material and the topographical and morphological characteristics of the catchment.

For each single mass, the following parameters have been measured: area $A_{m}$, length $L_{m}$, average slope $\theta$, average thickness $H$, porosity $n$, permeability $k$, internal friction angle $\Phi$ and the upstream subcatchment characteristics, in particular the area $A_{b}$, the runoff coefficient $\varphi$ and the slope $S$. The porosity and permeability values have been evaluated in a detailed study performed by Ghilardi et al. [27], assigning literature values checked with maps drawn up by the competent Authority (the Lombardy Region).

On the basis of field surveys, the thickness of the sediments have been assessed within the range 1-3 m. Table 2 shows the debris volumes and the upstream catchment characteristics, while Table $\mathbf{3}$ gives the movable volumes, as function of the mean thickness.

Different procedures are available, feasible to evaluate the probability of movement of a sediment mass [28]. According to Chen and Jan [28], the water depth that can move the mass is given by:

$$
m=\frac{\left[(\tan \theta-\tan \varphi) \cdot\left(G_{s}-G_{s} \cdot n+s_{s} \cdot n\right)\right]}{(\tan \theta-\tan \varphi) \cdot\left(1+s_{s} \cdot n-n\right)-\tan \theta}
$$

where:

$G_{s} \quad$ specific weight of the solid divided by the specific weight of the liquid $\left(G_{s}=\gamma_{s} / \gamma_{w}\right)$;

$\gamma_{s} \quad$ specific weight of the solid;

$\gamma_{w} \quad$ specific weight of the liquid (water);

$n \quad$ porosity; 
Table 2. Debris volumes and upstream catchment characteristics.

\begin{tabular}{|c|c|c|c|c|c|}
\hline & & & AM1 & AM2 & AM3 \\
\hline \multirow{9}{*}{$\begin{array}{l}\text { MASS CHARACTERIS- } \\
\text { TICS }\end{array}$} & Area & $A_{m}\left[\mathrm{~km}^{2}\right]$ & 0.266 & 0.237 & 0.132 \\
\hline & Maximum elevation & $H_{\max }\left[\begin{array}{ll}m a s l] \\
\end{array}\right.$ & 1400 & 1300 & 1150 \\
\hline & Minimum elevation & $H_{\min }\left[\begin{array}{ll}m & a s l\end{array}\right]$ & 900 & 890 & 944.74 \\
\hline & Length & $L_{m}[k m]$ & 0.861 & 0.666 & 0.519 \\
\hline & Mean slope & $\theta\left[^{\circ}\right]$ & 30.14 & 31.4 & 21.55 \\
\hline & Mean thickness & $H[m]$ & & $1-3$ & \\
\hline & Porosity & $n[-]$ & & 0.5 & \\
\hline & Permeability & $k[\mathrm{~m} / \mathrm{s}]$ & & 0.1 & \\
\hline & Int. friction angle & $\Phi\left[^{\circ}\right]$ & & 33 & \\
\hline \multirow{6}{*}{$\begin{array}{l}\text { UPSTREAM CATCHMENT } \\
\text { CHARACTERISTICS }\end{array}$} & Area & $A_{b}\left[k^{2}\right]$ & 0.158 & 0.113 & 0.976 \\
\hline & Maximum elevation & $h_{\max }\left[\begin{array}{ll}m & a s l\end{array}\right]$ & 1600 & 1400 & 1718.32 \\
\hline & Minimum elevation & $h_{\min }\left[\begin{array}{ll}m a s l\end{array}\right]$ & 1400 & 1300 & 1150 \\
\hline & Length & $L_{b}[\mathrm{~km}]$ & 0.252 & 0.156 & 0.903 \\
\hline & Mean slope & $S\left[^{\circ}\right]$ & 38.31 & 32.62 & 32.61 \\
\hline & Runoff coefficient & $\varphi[-]$ & 0.7 & 0.7 & 0.7 \\
\hline
\end{tabular}

Table 3. Debris movable volumes vs mean thickness.

\begin{tabular}{lccccc}
\hline \multicolumn{5}{c}{ Potentially movable volume $\left[\mathrm{m}^{3}\right]$} \\
\hline & $H=1.0 \mathrm{~m}$ & $H=1.5 \mathrm{~m}$ & $H=2.0 \mathrm{~m}$ & $H=2.5 \mathrm{~m}$ & $H=3.0 \mathrm{~m}$ \\
\cline { 2 - 5 }$A M 1$ & 266000 & 399000 & 532000 & 665000 & 798000 \\
$A M 2$ & 237000 & 355500 & 474000 & 592500 & 711000 \\
$A M 3$ & 132000 & 198000 & 264000 & 330000 & 396000 \\
\hline
\end{tabular}

$s_{s} \quad$ saturation of the solid;

$\theta \quad$ slope;

$\phi \quad$ stratification angle of the solid.

Known $m$ and $H$, the critical water depth $h$ to generate a slide is given by:

$$
h=m \cdot H
$$

while the discharge $Q$ through a vertical section of a sediment mass with height $H$ can be assessed as follows:

$$
Q=k \cdot h \cdot n \cdot l_{m}
$$

where $l_{m}$ is the mean width of the debris mass, defined as the ratio between its area and length along the direction of the maximum slope:

$$
l_{m}=\frac{A_{m}}{L_{m}}
$$

The critical intensity of the rainfall to generate $Q$ is given by:

$$
i=\frac{Q}{0,28 \cdot \phi \cdot A_{b}}
$$

with $A_{b}$ the area of the subcatchment upstream the debris mass.

For the Val Gola catchment $\phi=0.7$ has been selected on the basis of accurate hydrologic investigations [27].

On the basis of these parameters, further characteris- tics have been evaluated. Table 4 gives the return periods needed to move masses of debris flows of different thickness.

For masses so large, the hypothesis that they can collapse entirely at the same time cannot be accepted. So, these debris masses have been divided in "sub-masses", generated by different subcatchments.

Table 5 gives the return periods of the rainfalls that triggered the collapse of the debris flow sub-masses.

To achieve a more reliable assessment of the catchment instability, the well-known Shalstab code [29] was applied. To this end, the basin area has been divided with DEM cells of $20 \mathrm{~m} \times 20 \mathrm{~m}$ (Figure 4). The Figure 4 shows that about $65 \%$ of the area results to be unconditionally unstable (independently of the rainfall intensity) and for about $30 \%$ the stability depends on the rate between the rainfall intensity and the soil permeability. The remaining $5 \%$ of the catchment results unconditionally stable.

\section{CONCLUDING REMARKS}

With respect to the hazard assessment of a small torrent catchment of the Alps (Val Gola) different empirical methods have been applied with the aim of determining whether debris flow are likely to occur or not.

Each of the considered methods shows both advantages and shortcomings. The wise application and a 
Table 4. Return period of the rainfall necessary to move the debris flow volume (function of the average depth).

\begin{tabular}{lccccc}
\hline$H[\mathrm{~m}]$ & 1.0 & 1.5 & 2.0 & 2.5 & 3.0 \\
\hline$A M 1$ & $<5$ & $5-10$ & $10-20$ & $20-50$ & $100-200$ \\
$A M 2$ & $<5$ & $<5$ & $5-10$ & $10-20$ & $20-50$ \\
$A M 3$ & $<5$ & $<5$ & 10 & $20-50$ & $50-100$ \\
\hline
\end{tabular}

Table 5. Return period $\mathrm{T}$ of the rainfall necessary to move the sub-masses of the volume AM1.

\begin{tabular}{cccccc}
\hline \multirow{2}{*}{1.0} & $T<5$ & $T<5$ & $T<5$ & $T<5$ & $T<5$ \\
& $V=15000 \mathrm{~m}^{3}$ & $V=50000 \mathrm{~m}^{3}$ & $V=123000 \mathrm{~m}^{3}$ & $V=219000 \mathrm{~m}^{3}$ & $V=266000 \mathrm{~m}^{3}$ \\
\multirow{2}{*}{1.5} & $T<5$ & $T<5$ & $T<5$ & $T=10-20$ & $T=5-10$ \\
& $\mathrm{~V}=22500 \mathrm{~m}^{3}$ & $V=75000 \mathrm{~m}^{3}$ & $V=184500 \mathrm{~m}^{3}$ & $V=328500 \mathrm{~m}^{3}$ & $V=399000 \mathrm{~m}^{3}$ \\
\hline \multirow{2}{*}{2.0} & $T<5$ & $T<5$ & $T=5$ & $T=50$ & $T=10-20$ \\
& $\mathrm{~V}=30000 \mathrm{~m}^{3}$ & $V=100000 \mathrm{~m}^{3}$ & $V=246000 \mathrm{~m}^{3}$ & $V=438000 \mathrm{~m}^{3}$ & $V=532000 \mathrm{~m}^{3}$ \\
\hline \multirow{2}{*}{2.5} & $T<5$ & $T<5$ & $10-20$ & $T=100-200$ & $T=20-50$ \\
& $V=37500 \mathrm{~m}^{3}$ & $V=125000 \mathrm{~m}^{3}$ & $V=307500 \mathrm{~m}^{3}$ & $V=547500 \mathrm{~m}^{3}$ & $V=665000 \mathrm{~m}^{3}$ \\
\hline 3.0 & $T<5$ & $T<5$ & $20-50$ & $T>200$ & $T=100-200$ \\
& $\mathrm{~V}=45000 \mathrm{~m}^{3}$ & $V=150000 \mathrm{~m}^{3}$ & $V=369000 \mathrm{~m}^{3}$ & $V=657000 \mathrm{~m}^{3}$ & $V=798000 \mathrm{~m}^{3}$ \\
\hline
\end{tabular}
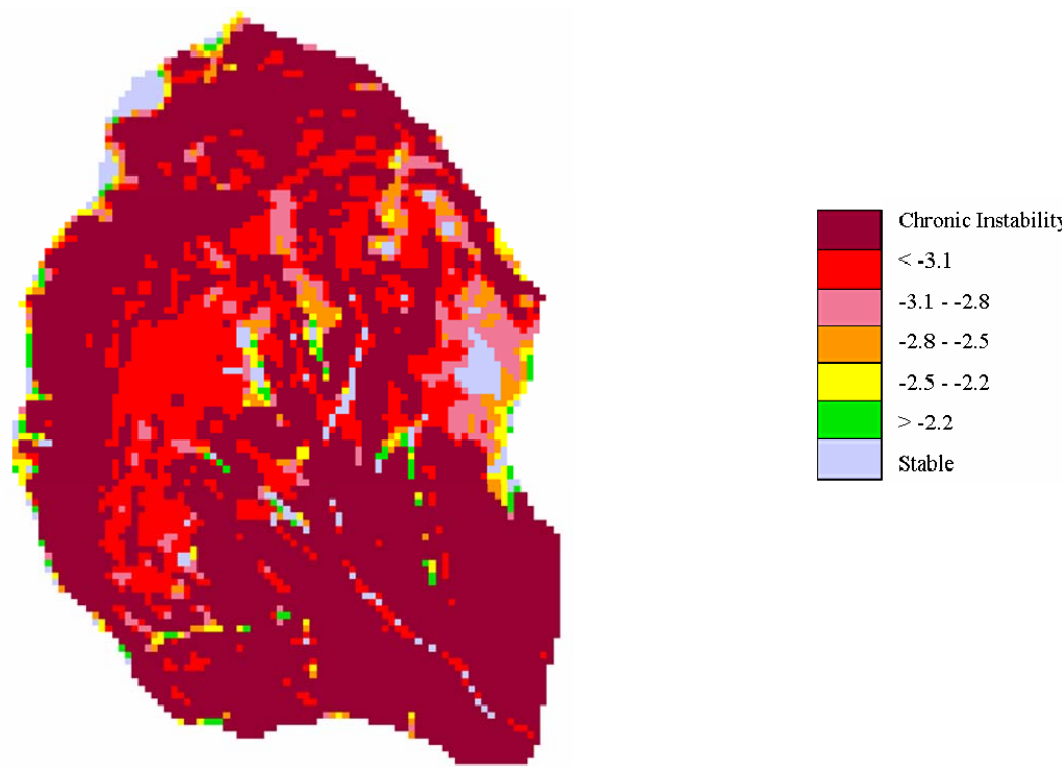

Figure 4. Evaluation of the stability of the catchment performed with the Shalstab program. Cells characterised by chronic instability, complete stability and those which are unstable from the hydrologic point of view are reported in the legend. Practically the whole catchment has to be considered unstable.

cross-check of different estimation approaches can help attenuate the intrinsic limitations of each single method, offering a more reliable assessment of the bent of a catchment to generate debris flows.

Such relationships can be improved if hydrologic and hydraulic parameters and factors controlling sediment supply are also taken into account. At present it is agreed that a better knowledge of the hydrologic characteristics of the catchment and a more detailed assessment in the field of the material likely to be mobilized may be the best approach to achieve a more precise estimate of a possible debris flow volume. Once a design debris flow volume has been determined, a number of other important parameters characterizing debris flow behaviour can be estimated, as shown in this work.

Further studies are in progress, with the uses of physically based mathematical models, suitable to describe in a more realistic way the triggering, propagation and deposition processes of debris flows, in order to design more efficient structural and non-structural defence measures. 


\section{REFERENCES}

[1] Zimmerman, M., Mani, P. and Romang, H. (1997) Magnitude-frequency aspects of alpine debris flow. Eclogae Geologicae Helvetiae, 90, 415-420.

[2] Rickenmann, D. (1999) Empirical relationships for debris flows. Natural Hazards, 19, 47-77. doi:10.1023/A:1008064220727

[3] Marchi, L., Arattano, M. and Deganutti, A.M. (2002) Ten years of debris-flow monitoring in the Moscardo Torrent (Italian Alps). Geomorphology, 46, 1-17. doi:10.1016/S0169-555X(01)00162-3

[4] Melton, M.A. (1965) The geomorphic and paleoclimatic significance of alluvial deposits in Southern Arizona. Journal of Geology, 73, 1-38. doi:10.1086/627044

[5] Aulitzky, H. (1980) Preliminary two-fold classification of torrents. Proceedings of International Symposium, Austria, 285-310.

[6] Nakamura, J. (1980) Investigation manual on prediction of occurence od Dosekiryu [debris flow] delineation of sangerous zone affected by Dosekiryu and arrangement of warning and evacuation system in mountain torrents in Japan. Proceedings of International Symposium, Austria, 41-81.

[7] Hungr, O. (1995) A model for the runout analysis of rapid flow slides. Canadian Geotechnical Journal, 32, 610-623. doi:10.1139/t95-063

[8] Hampel, R. (1977) Geschiebewirtschaft in Wildbächen [sediment budget of torrents]. Wildbach-und Lawinenverbau, 41, 3-34 (in German).

[9] Marchi, L. and Tecca, P.R. (1996) Magnitudo delle colate detritiche nelle Alpi Orientali. Italiane Geoingegneria Ambientale e Mineraria, 33, 79-86. (in Italian).

[10] D’Agostino, V. (1996) Analisi quantitativa del trasporto solido torrentizio nei bacini montani del Trentino Orientale in "Scritti dedicati a Giovanni Tournon". Associazione italiana di Ingegneria agraria-Associazione Idrotecnica Italiana, Novara (Italy), 111-123 (in Italian).

[11] D’Agostino, V., Cerato, M. and Coali, R. (1996) Extreme events of sediment transport in the eastern Trentino torrents. Atti del Convegno Interpraevent, 1, 377-386.

[12] D’Agostino, V. and Marchi, L. (2004) Estimation of debris-flow magnitude in the Eastern Italian Alps. Earth Surface Processes and Landforms, 29, 207-220. doi:10.1002/esp.1027

[13] Bianco, G. and Franzi, L. (2000) Estimation of debris flow volumes from storm events. Proceedings of Debris Flow Mitigation: Mechanics, Prediction and Assessment, Taipei, Taiwan, 441-448.

[14] Bottino, G., Crivellari, R. and Mandrone, G. (1996) Eventi pluviometrici critici e dissesti: Individuazione delle soglie d'innesco di colate detritiche nell'anfiteatro morenico di Ivrea. Proceedings of La prevenzione delle catastrofi idrogeologiche: il contributo alla ricerca scientifica, Alba (Torino), 201-210.

[15] Takahashi, T., Sawada, T., Suwa, H., Mizuyama, T., Mizuhara, K., Wu, J., Tang, B., Kang, Z., Zhou, B. (1994)
Japan-China joint research on the prevention from debris flow hazards. Research Report, Japanese Ministry of Education, Science and Culture, International Scientific Research Program, No. 03044085.

[16] Kronfellner-Kraus, G. (1984) Extreme feststofffrachten und grabenbildungen von wildbächen [extreme sediment loads and erosion of torrents]. Proceedings of International Symposium Interpraevent, Villach, Austria, 2, 109-118 (in German).

[17] Tropeano, D. and Turconi, L. (1999) Valutazione del potenziale detritico in piccoli bacini delle Alpi Occidentali e Centrali. CNR-IRPI/GNDCI, Pubbl. n. 2058 Linea 1, 151.

[18] Johnson, P.A., McCuen, R.H. and Hromadka, T.V. (1990) Magnitude and frequency of debris flow. Journal of Hydrology, 123, 69-82. doi:10.1016/0022-1694(91)90069-T

[19] Meunier, M., Rickenmann, D. and Rahuel, J.L. (2000) Workshop 3-torrential hazard-general in "risques naturel en montagne”. In: Gillet, F. and Zanolini, F., Eds., Cemagref Editions, France, 329-333.

[20] Ceriani, M., Fossati, D. and Quattrini, S. (1998) Valutazione della pericolosità idrogeologica sulle conoidi alpine; esempio della metodologia di Aulitzky applicata alla conoide del torrente Re di Gianico-Valcamonica (Bs) -Alpi Centrali. Atti del XXVI Convegno di Idraulica e Costruzioni Idrauliche, Catania (in Italian).

[21] Armanini, A. (1996) Colate di detrito. Rapporti di lavoro dell'Istituto Geologico della Repubblica Italiana e del Cantone del Ticino (in Italian).

[22] Soil Conservation Service Hydrology National Engineering Handbook (1956) Section 4, Washington D.C., U.S.A.

[23] Wooding, R.A. (1965) A hydraulic model for the catchment stream problem. Kinematic wave theory. Journal of Hydrology, 3, 254-267. doi:10.1016/0022-1694(65)90084-3

[24] Mignosa, P. (1989) Sui problemi di dimensionamento delle reti di drenaggio urbano. Dissertazione per il conseguimento del titolo di Dottore di Ricerca, Istituto di Idraulica, Politecnico di Milano (in Italian).

[25] Schoklitsch, A. (1962) Handbuch des Wasserbaues, Springer, Wien (in German).

[26] Marchi, L. and D’Agostino, V. (2004) Estimation of debris flow magnitude in the eastern Italian Alps. Earth Surface Processes and Landforms, 29, 207-220. doi:10.1002/esp.1027

[27] Ghilardi, F., Ghilardi, S. and Mambretti, S. (2006) Studio di dettaglio della conoide della Val Gola in comune di Costa Volpino Relazione Tecnica (in Italian).

[28] Chen, J.C. and Jan, C.D. (2000) Debris flow occurrence probability on hillslopes. Proceedings of Debris Flow Mitigation: Mechanics, Prediction and Assessment, Balkema, Rotterdam.

[29] Montgomery, D.R and Dietrich, W.E. (1994) A physically based model for the topographic control on shallow landsliding. Water Resources Research, 30, 1153-1171. doi:10.1029/93WR02979 